\title{
Modelling of the Response of Partially Saturated Non-cohesive Soil Subjected to Undrained Loading
}

\author{
Waldemar Świdziński, Jacek Mierczyński, Marcin Smyczyński \\ Institute of Hydro-Engineering, Polish Academy of Sciences, Kościerska 7, 80-953 Gdańsk, Poland, \\ emails: waldek@ibwpan.gda.pl, mier@ibwpan.gda.pl, m.smyczynski@ibwpan.gda.pl
}

(Received November 27, 2017; revised March 1, 2018)

\begin{abstract}
The paper deals with the modelling of the undrained response of non-cohesive partially saturated soils subjected to triaxial compression. The model proposed is based on an incremental equation describing the pre-failure response of non-cohesive soils during shearing. The original model, developed by Sawicki, was modified by taking into account pore fluid compressibility. The governing equation makes it possible to simulate effective stress paths under undrained conditions. Numerical results are compared with experimental data.
\end{abstract}

Key words: partial saturation, undrained conditions, incremental equations

\section{Introduction}

The results of experimental investigations of partially saturated non-cohesive soils (pure sands and gravels, as well as sands with some fine fraction) subjected to shear under undrained conditions clearly indicate that such soils can also liquefy. This is an important practical finding, since in nature we often encounter partially saturated media, especially in soil layers above the free water table and sometimes below it, see e.g. Jamiolkowski (2014) or Nakazawa et al (2004). The measurements of the P-wave velocity in layers of soil in the first $5 \mathrm{~m}$ below the water table show that its value ranges from 500 to $1000 \mathrm{~m} / \mathrm{s}$ and therefore is significantly lower than $1600 \mathrm{~m} / \mathrm{s}$ observed in fully saturated media (Kamata et al 2009). In some cases, the thickness of partially saturated layers may be significant. Such a situation occurs, for example, in post-flotation tailings facilities, where the zone of partial saturation can reach as deep as $20 \mathrm{~m}$ (Świdziński et al 2017).

Some additional words of explanation requires the term "partially saturated", which defines the range of potential "unsaturation" at which one can expect pore water pressure generation under shearing which can lead to liquefaction for contractive states. Sometimes, the terms such as "imperfectly", "partly", "near" or "nearly" saturated are used instead (e.g. Nakazawa et al 2004, Ishihara et al 2004) to reflect small 
amount of air in pore fluid which however can significantly change its compressibility. For many types of non-cohesive soils such a small amount of air considered corresponds to high values of saturation degree $\left(S_{r}\right)$, sometimes close to unity.

This issue is well illustrated in Fig. 1 (from Nakazawa et al (2004) paper) which shows distribution of air content along the schematic soil profile together with corresponding distribution of P-wave velocity. For the sake of this paper, the term "partially saturated" will be used with reference to the zone indicated in Fig. 1.

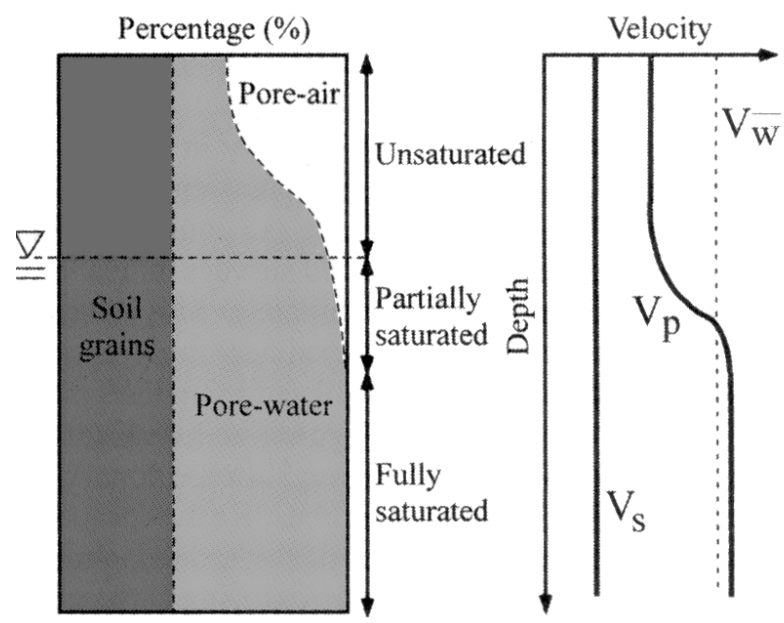

Fig. 1. Distribution of pore air content and P-wave velocity (after Nakazawa et al 2004)

In order to investigate the effect of partial saturation on the undrained shear strength of the soil, a series of triaxial compression tests were performed on the same soil, with a similar initial stress state, but with different levels of water saturation controlled by Skempton's coefficient $B$. Experiments were conducted on initially contractive samples of selected tailings characterised by the highest value of the sand fraction ratio SFR (low content of fine fraction $\approx 6 \%$ ). The test series included both monotonic and cyclic loads (Świdziński et al 2017). The studies show that even partially saturated soils can easily liquefy, although with a decrease in saturation, their behaviour under undrained conditions tends to the response of these soils with full drainage.

Moreover, the impact of saturation on seismic wave propagation (mainly of the P-wave) was investigated. Its velocity may be a measure of soil deformability and can also be used for precise identification of the fully saturated zone in situ. In this case, as well, the results obtained confirm previous conclusions of other authors (cf. e.g. Yang et al 2004).

In this paper, an attempt is made to describe theoretically the behaviour of non-cohesive initially contractive and partially saturated soil subjected to monotonic undrained triaxial compression. Based on the concept proposed by Sawicki (2008), a differential equation was derived for the theoretical prediction of pore pressure gen- 
eration as a function of Skempton's coefficient $B$. Necessary functions, namely the compressibility of pore fluid (gas-water mixture) as a function of pressure, as well as generalised compressibility coefficients of the soil skeleton as functions of the stress state (mean effective stress and deviator stress), were determined experimentally. The proposed theoretical model was validated by experimental data.

\section{Basic Concepts and Relationships}

In geotechnical nomenclature, the concepts of unsaturated and partially saturated soils exist independently. The term "partial saturation" has been introduced to distinguish full saturation from conditions of incomplete pore saturation with water. In other words, partial saturation refers to a state between incomplete and full saturation.

To precisely define both states, as well as to determine their role in the generation of pore pressure under undrained conditions, it is worthwhile to take a closer look at basic concepts and relationships.

\subsection{Suction Pressure}

The basic difference between saturated and unsaturated soils of any kind (cohesive or non-cohesive) is related to the presence of suction pressure due to the difference between pore water pressure $\left(p_{w}\right)$ and pore air pressure in the gas space of the same pores $\left(p_{a}\right)$. As shown by the results of studies, the suction pressure is only significant for soils with a high content of the fine fraction, since porous spaces in coarse soils (sand, gravel) are so large that the suction pressure resulting from the incomplete filling of pores with water is negligibly low (Bian and Shahrour 2009).

Fig. 2 presents a water retention curve for Hostun sand, which shows that suction pressure remains low (below $5 \mathrm{kPa}$ ) over a wide range of the degree of saturation $S_{r}$.

It can be seen that for degrees of saturation $S_{r}$ above $20 \%$ soil suction is very low, so the pore water pressure will be approximately equal to the pore air pressure $\left(p_{w}=p_{a}\right)$, hence the use of Terzaghi's effective stress principle is fully justified (Bian and Shahrour 2009). In the remainder of the paper, this principle was adopted in the definition of effective stresses and in the description of pore pressure generation for a partially saturated soil medium.

\subsection{Response of Partially Saturated Soils Subjected to Shearing}

The response of partially saturated soils is directly related to the compressibility of the liquid filling soil pores, as it affects the processes occurring in soil subjected to load under undrained conditions. Shearing of an initially contractive soil causes the tendency to reduce the volume of the pores and the fluid that fills them, resulting in increased fluid pressure. The less compressible is the fluid filling the pores, the greater the increase in pressure. This results in a decrease in the mean effective stress and 


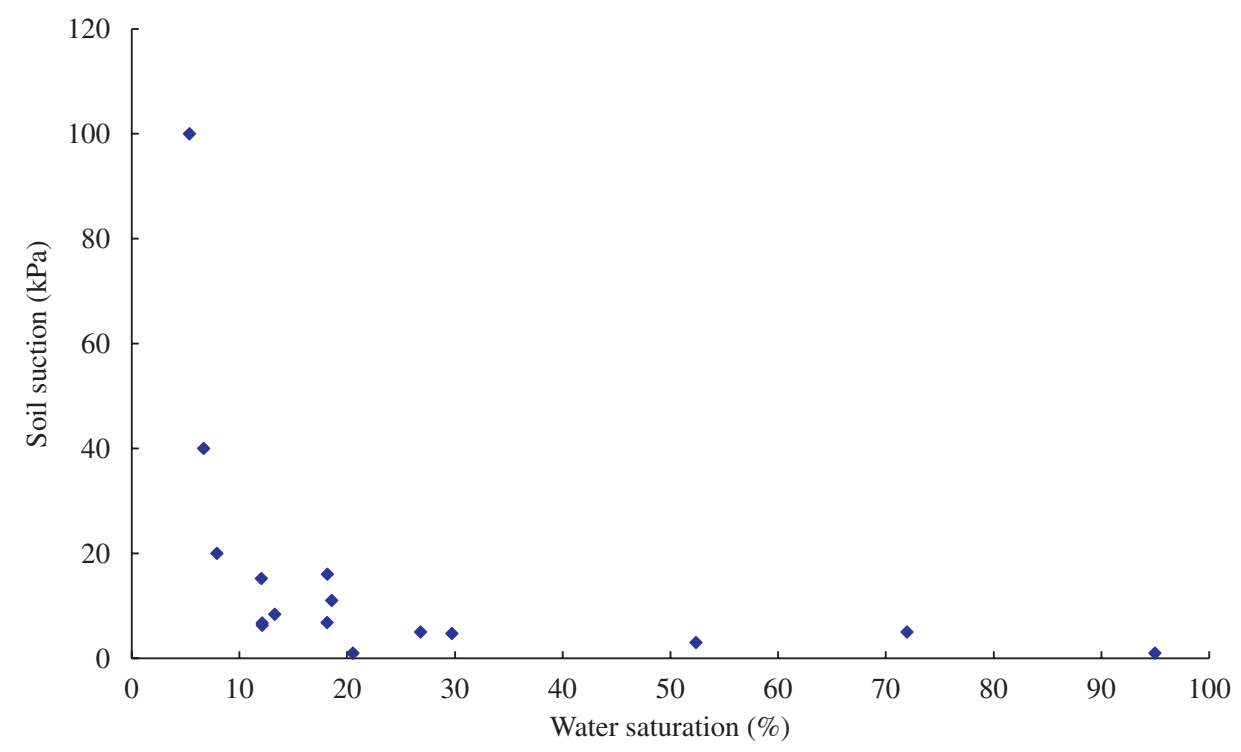

Fig. 2. Retention curve for Hostun sand (Bian and Shahrour 2009)

a subsequent reduction in the shear strength of the soil. In the extreme case, effective stress vanishes, the soil cannot transfer the shear stress and liquefies.

The response of saturated soil to load applied under undrained conditions can be described by a formula derived by Skempton (1954), according to which the rise in pore water pressure due to monotonic loading (expressed by the principal stresses) under triaxial compression conditions can be written in the following form:

$$
\Delta u=B\left(\Delta \sigma_{3}+A \Delta q\right)
$$

where $u$ is pore water pressure, $\sigma_{3}$ is water pressure in the triaxial chamber, while $A$ and $B$ are coefficients corresponding to the increase in pore pressure due to deviatoric $q$ and isotropic $p$ loads, respectively.

For triaxial compression conditions, the mean and deviator stress are defined as

$$
\begin{gathered}
p=\frac{1}{3}\left(\sigma_{1}+2 \sigma_{3}\right), \\
q=\sigma_{1}-\sigma_{3}
\end{gathered}
$$

where $\sigma_{1}$ is the axial stress.

After simple transformations with the use of Eqs. (2) and (3), Eq. (1) can be written as

$$
\Delta u=B\left(\Delta p+\frac{3 A-1}{3} \Delta q\right)
$$


In the case of isotropic compression $(\Delta q=0)$, we obtain

$$
B=\frac{\Delta u}{\Delta p=\Delta \sigma_{3}} .
$$

The formula for Skempton's parameter $B$ can be derived in an elementary way. Figure 3 shows a phase diagram of a water-gas-soil skeleton medium. Basic properties of a soil skeleton such as the porosity $n$ and the void ratio $e$ are defined as follows:

$$
n=\frac{V_{p}}{V}, \quad e=\frac{V_{p}}{V_{s}} .
$$
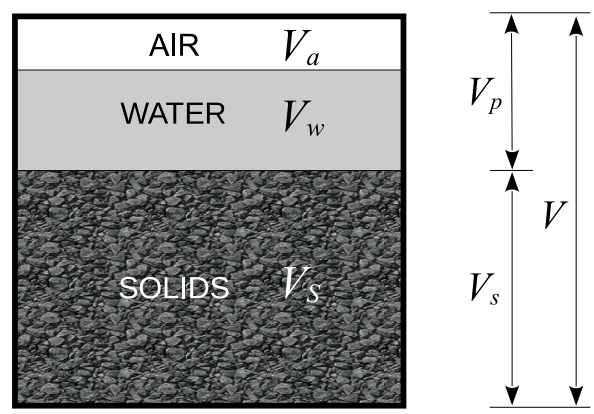

Fig. 3. Elementary volume of soil medium

The coefficient of compressibility $\kappa_{f}$ of the water-gas mixture filling the soil pores (inverse of the compressibility modulus $K_{f}$ ) determines the relationship between the relative volume change of the fluid $\Delta \varepsilon_{f}=\Delta V_{p} / V_{p}$ and the change in pore pressure $\Delta u$ (at constant temperature):

$$
\kappa_{f}=\frac{1}{K_{f}}=\frac{\Delta \varepsilon_{f}}{\Delta u}=\frac{\Delta V_{p}}{V_{p}} \frac{1}{\Delta u} .
$$

Hence the change in pore volume can be written as

$$
\Delta V_{p}=\kappa_{f} V_{p} \Delta u=\kappa_{f} n V \Delta u .
$$

The compressibility of the soil skeleton $\kappa_{s}$, which determines the relation between the relative volume change in the soil skeleton $\Delta \varepsilon_{v}=\Delta V / V$ caused by the corresponding change in stress $\left(\Delta \sigma_{3}=\Delta p^{\prime}\right)$, can be expressed as

$$
\kappa_{s}=\frac{1}{K_{s}}=\frac{\Delta \varepsilon_{v}}{\Delta \sigma_{3}^{\prime}}=\frac{\Delta V}{V} \frac{1}{\Delta \sigma_{3}^{\prime}} .
$$

Thus we obtain

$$
\Delta V=\kappa_{s} V \Delta \sigma_{3}^{\prime}=\kappa_{s} V\left(\Delta \sigma_{3}-\Delta u\right)
$$


Assuming that volume changes in both the pores and the soil skeleton must be the same $\left(\Delta V_{p}=\Delta V\right)$, the formula for Skempton's parameter $B$ is obtained from Eqs. (8) and (10):

$$
B=\frac{\Delta u}{\Delta \sigma_{3}}=\frac{1}{1+n \frac{K_{f}}{\kappa_{s}}}=\frac{1}{1+n \frac{K_{s}}{K_{f}}} .
$$

In completely saturated soil, $B=1$ because the compressibility of water is negligibly low in comparison to the compressibility of the soil skeleton $\left(\kappa_{f} / \kappa_{s}=0\right)$. In partially saturated soil, we have $0<B<1$ since even a very small air content in the pore fluid significantly influences its compressibility (increasing it by several orders of magnitude).

Eq. (5) is practically used to check the level of saturation of samples with water in triaxial compression tests. The level of saturation is checked by examining the value of the parameter $B$ by measuring the change in pore water pressure caused by the change in cell pressure (with a closed drainage valve). If the result is unsatisfactory, pore pressure is increased by increasing back pressure, and the value of $B$ is re-checked. The procedure is repeated until the target saturation level, usually close to unity, is reached. Increasing the pore water pressure results in a decrease in pore water compressibility, $B \simeq 1$ is obtained by satisfying the condition $\kappa_{f} \ll \kappa_{s}$. The compressibility of the pore fluid and the soil skeleton should differ by at least one order of magnitude - then for $\kappa_{f} / \kappa_{s}<10$ and, for example, with $n=0.4$, we obtain $B>0.96$ (Mierczyński 2001).

In soil mechanics, the level of saturation of pores with water is defined by the degree of saturation $S_{r}$, which is a measure of the filling of the porous space with liquid (Fig. 3):

$$
S_{r}=\frac{V_{w}}{V_{p}} .
$$

According to Verruijt (1969), the relationship between the compressibility modulus of a pore fluid (air-water mixture) and the degree of saturation $S_{r}$ is the following:

$$
K_{f}=\frac{1}{\frac{S_{r}}{K_{w}}+\frac{1-S_{r}}{p_{w}}}
$$

where $p_{w}$ is the absolute pressure, and $K_{w}$ is the compressibility modulus of water.

Hence, using Eq. (11), we obtain the following relationship between the degree of saturation $S_{r}$ and Skempton's coefficient $B$ (Yang 2002):

$$
B=\frac{1}{1+\frac{S_{r} K_{s}}{K_{w}}+n K_{s} \frac{1-S_{r}}{p_{w}}} .
$$


The compressibility modulus of the soil skeleton (which is generally stress dependent) can be calculated, for example, on the basis of the shear modulus $G$ and Poisson's ratio $v$ :

$$
K_{s}=\frac{2 G(1+v)}{2(1-2 v)} .
$$

Figure 4 shows changes in shear wave velocity as a function of the mean effective pressure obtained from multiple triaxial tests using piezoelectric sensors. The tests were performed out on undisturbed samples taken from the TSF (Tailings Storage Facility) Żelazny Most at about $40 \mathrm{~m}$ from the crest of the dam (Geoteko 2012). The same tailings (designated as Os50) were used in triaxial tests in which the impact of partial saturation conditions was studied (see Świdziński et al 2017).

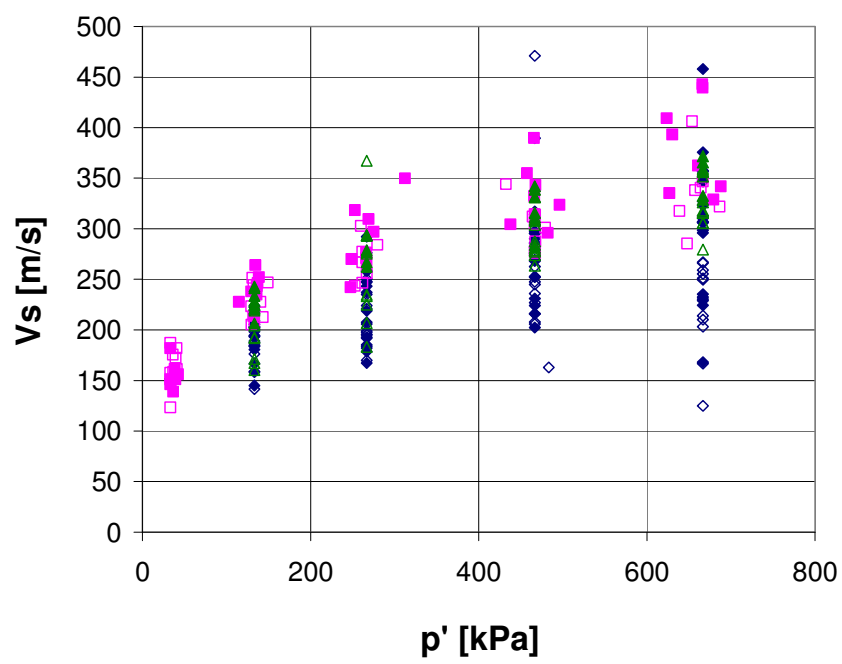

Fig. 4. Influence of mean effective stress on shear wave velocity (in undisturbed samples of tailings collected $40 \mathrm{~m}$ from the dam's crest, Geoteko 2012)

Figure 5 shows changes in Skempton's coefficient $B$ as a function of the degree of saturation $S_{r}$. This graph was obtained using Eq. (14) with a value of the shear modulus $G$ based on the results of shear wave velocity measurements in the material analysed. For a mean effective stress $p^{\prime}=400 \mathrm{kPa}$, the average velocity $v_{s}=250 \mathrm{~m} / \mathrm{s}$. Hence, $G=89 \mathrm{MPa}$, the bulk compressibility modulus $K_{s}=149 \mathrm{MPa}$ (with Poisson's ratio $v=0.25$ ). The average porosity $n$ of the samples tested was 0.465 . Please note that since the $B$-check was performed at $p^{\prime}=20 \mathrm{kPa}$, whereas $G$ value was determined for $p^{\prime}=400 \mathrm{kPa}$, therefore it was respectively reduced assuming well known relationship $G^{m} \sim p^{\prime}$ and $m=2$. For comparison, in Fig. 5 another $B\left(S_{r}\right)$ dependence for $K_{s}$ resulting from compression curve (see Fig. 7) was shown.

Figure 5 suggests that even for low values of $B$ (nearly 0.2 ), the degree of saturation of the soil tested may be very high, close to unity whereas at $S_{r}$ values below 0.8 , 


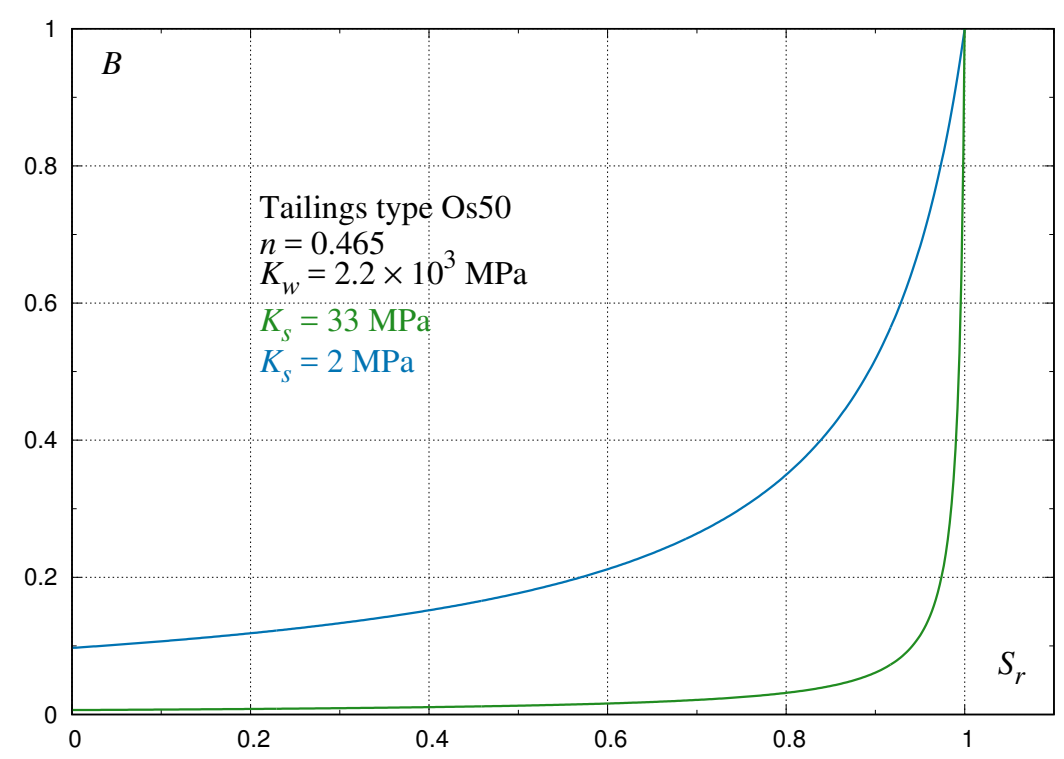

Fig. 5. Relationship between Skempton's coefficient $B$ and degree of saturation $S_{r}$

the $B$ coefficient tends to zero (green line), which, according to Skempton's equation, means that excess pore pressure will not be generated. Similar behaviour was reported by other authors, (Yang et al 2004, Kamata et al 2009). Therefore, it is assumed that the partially saturated zone, as opposed to the unsaturated zone, is usually limited by the saturation ratio 0.8 , and the state of partial saturation can be well defined by the parameter $B$ (Kamata et al 2009).

This is an important observation because it shows that the generation of pore pressure under undrained conditions can take place only with a significant saturation of pores with water. When the saturation is lower, pore water pressure does not generate and soil behaviour tends to that corresponding to drained conditions.

Hence, in the further part of this work, the relations and theoretical descriptions will refer to soil with pores almost completely filled with water and with air present only in the form of occluded bubbles.

Suppose that the pore fluid is practically incompressible water with a small amount of gas bubbles. Then, Eq. (7) can be written as

$$
\kappa_{f}=\frac{\Delta V_{p}}{V_{p}} \frac{1}{\Delta u}=\frac{\Delta V_{a}+\Delta V_{w}}{V_{p}} \frac{1}{\Delta u} .
$$

According to the definition, the air compressibility coefficient $\kappa_{a}$ has the following form:

$$
\kappa_{a}=\frac{1}{K_{a}}=\frac{\Delta V_{a}}{V_{a}} \frac{1}{\Delta u}=\frac{\Delta V_{a}}{V_{p}} \frac{V_{p}}{V_{a}} \frac{1}{\Delta u}=\frac{\Delta V_{a}}{V_{p}} \frac{1}{\Delta u\left(1-S_{r}\right)} .
$$


Similarly, the coefficient of water compressibility $\kappa_{w}$ can be written as

$$
\kappa_{w}=\frac{1}{K_{w}}=\frac{\Delta V_{w}}{V_{w}} \frac{1}{\Delta u}=\frac{\Delta V_{w}}{V_{p}} \frac{V_{p}}{V_{w}} \frac{1}{\Delta u}=\frac{\Delta V_{w}}{V_{p}} \frac{1}{\Delta u S_{r}} .
$$

Hence, using Eqs. (16)-(18), we obtain a linear equation describing the change in the coefficient of compressibility of the water-gas mixture depending on the degree of saturation $S_{r}$ :

$$
\kappa_{f}=\left(1-S_{r}\right) \kappa_{a}+S_{r} \kappa_{w}=\left(\kappa_{w}-\kappa_{a}\right) S_{r}+\kappa_{a}
$$

or

$$
\kappa_{f}=(1-N) \kappa_{w}+N \kappa_{a}
$$

where $N$ is the relative volumetric air content in the water-gas mixture.

The compressibility of a mixture depends on the compressibility and the relative content of its components. This formula, originally proposed by Fredlund and Rahardjo (1993), can also be expressed in terms of bulk moduli of the individual components:

$$
K_{f}=\frac{1}{\kappa_{f}}=\frac{K_{a} K_{w}}{K_{w}+S_{r}\left(K_{a}-K_{w}\right)} .
$$

The bulk modulus (the inverse of the compressibility coefficient, Eqs. (17) and (18)) of completely deaerated water is approximately $1 /\left(4.5 \times 10^{-10} \mathrm{~m}^{2} / \mathrm{N}\right)=2.22 \times$ $10^{3} \mathrm{MPa}$, while the air modulus is of the order of its pressure $(0.1 \mathrm{MPa})$. The compressibility of air is therefore 4 orders of magnitude greater than that of water, so a small amount of air contained in water can dramatically change the compressibility of such a mixture.

\section{Theoretical Description of the Response of Partially Saturated Non-cohesive Soil Subjected to Triaxial Compression}

\subsection{Governing Equations}

In the general form, the volumetric deformation of the soil skeleton $\varepsilon_{v}$ under triaxial compression conditions is a function of the mean effective stress and the stress deviator:

$$
\varepsilon_{v}=f\left(p^{\prime}, q\right)
$$

or alternatively

$$
\varepsilon_{v}=f\left(p^{\prime}, \eta\right)
$$

where $\eta$ is a stress ratio given by the following equation:

$$
\eta=\frac{q}{p^{\prime}} .
$$


If we choose Eq. (23), the change in the volumetric strain of the soil skeleton $\varepsilon_{v}$ can be formally written as (Sawicki 2008)

$$
d \varepsilon_{v}=\left(\frac{\partial \varepsilon_{v}}{\partial p^{\prime}}\right) d p^{\prime}+\left(\frac{\partial \varepsilon_{v}}{\partial \eta}\right) d \eta
$$

Eq. (25) has a form similar to one of the two incremental equations proposed by Sawicki (2008), describing the development of volumetric and deviatoric strains in dry sand subjected to monotonic triaxial loading and unloading, see also Sawicki and Świdziński (2010).

According to Eq. (9), the partial derivatives in Eq. (25) are generalised compressibility coefficients of the soil skeleton characterising its response, respectively, at isotropic compression $(q=0, \eta=0=$ const $)$ and pure shearing $\left(p^{\prime}=\right.$ const $)$, which can be formally written as

$$
d \varepsilon_{v}=\kappa_{s}^{p^{\prime}} d p^{\prime}+\kappa_{s}^{\eta} d \eta
$$

where, in general,

$$
\kappa_{s}^{p^{\prime}}\left(e, p^{\prime}, \eta\right)=\left(\frac{\partial \varepsilon_{v}}{\partial p^{\prime}}\right)_{\eta=\mathrm{const}}
$$

and

$$
\kappa_{s}^{\eta}\left(e, p^{\prime}, \eta\right)=\left(\frac{\partial \varepsilon_{v}}{\partial \eta}\right)_{p^{\prime}=\mathrm{const}} .
$$

Generalised coefficients of compressibility correspond to the basic functions $\boldsymbol{M}$ and $\boldsymbol{N}$ in one of the two incremental equations proposed by Sawicki (2008).

According to the same assumption as in Eq. (11), the identity of the pore and soil skeleton volume changes $\left(\Delta V_{p}=\Delta V\right)$ gives

$$
d \varepsilon_{v}=n d \varepsilon_{f}
$$

and from Eq. (7) we obtain

$$
d \varepsilon_{f}=\kappa_{f} d u .
$$

Hence, on the basis of Eqs. (26), (29) and (30), we obtain a formula describing the changes in pore pressure induced by triaxial compression under undrained conditions, (see Sawicki and Świdziński, 2007):

$$
\kappa_{s}^{p^{\prime}} d p^{\prime}+\kappa_{s}^{\eta} d \eta=n \kappa_{f} d u .
$$

It should be noted that, under undrained conditions, the incremental equation describing pore pressure generation proposed by Sawicki and Świdziński (2007) takes the form of the equation derived by Skempton (1954), see Eq. (4). 
Some transformations of Eq. (31) with the use of Eqs. (2), (3) and (24) and Terzaghi's effective stress principle, allow us to eliminate one variable and obtain the following form of a differential equation:

$$
\frac{\partial p^{\prime}}{\partial \eta}=\frac{n \kappa_{f} p^{\prime}-3 \kappa_{s}^{\eta}}{3\left(\kappa_{s}^{p^{\prime}}+n \kappa_{f}\right)-n \kappa_{f} \eta} .
$$

The integration of Eq. (32) makes it possible to reconstruct the stress path in the $\left(p^{\prime}, \eta\right)$ space or, after applying formula $(24)$, in the $\left(p^{\prime}, q\right)$ space for any value of the compressibility coefficient $\kappa_{f}$ and, according to Eq. (11), for any value of Skempton's parameter $B$, which determines the level of partial saturation. It should be noted, however, that the above differential equation is valid only when the standard geotechnical triaxial stress path is applied, that is, when cell pressure is kept constant.

\subsection{Compressibility of a Water-gas Mixture}

In the general form, the compressibility coefficient of a mixture of water and gas is a function of pressure and relative gas content $\kappa_{f}\left(p_{w}, N\right)$. Using the ideal gas law and Eq. (20), this coefficient can be written as (Fredlund 1976, Mierczyński 2001)

$$
\kappa_{f}\left(N_{0}, p_{w}\right)=(1-N) \kappa_{w}+N \kappa_{a}=\left(1-N_{0} \frac{p_{0}}{p_{w}}\right) \kappa_{w}+\frac{N_{0}}{p_{0}}\left(\frac{p_{0}}{p_{w}}\right)^{2}
$$

where $N_{0}=N\left(p_{0}\right)$ is the relative volumetric gas content in water at atmospheric pressure $\left(p_{0}=100 \mathrm{kPa}\right)$. Figure 6 shows changes in the compressibility coefficient of the mixture, obtained from Eq. (33), as a function of pressure change for different gas contents in the mixture.

Skempton's coefficient $B$ corresponding to assumed initial gas content $N_{0}$ (or $S_{r 0}=1-N_{0}$ ) can be determined with the use of Eqs. (14) and (33), from which we obtain $B=B\left(\kappa_{s}, N_{0}, p_{w}\right)$, where $p_{w}=p_{0}+u$ and $u$ is the initial pore pressure.

When comparing theoretical and experimental results it is much more practical to use $B$-value as a common parameter due to its much easier measurement during a triaxial test than reliable determination of a soil sample's saturation $\left(S_{r}\right)$.

\subsection{Compressibility of the Soil Skeleton}

The generalised coefficients of soil skeleton compressibility (Eq. 32) describe soil deformations caused by compression $\left(\kappa_{s}{ }^{\prime}\right)\left(\Delta p^{\prime} \neq 0\right)$ and pure shearing $\left(\kappa_{s}^{\eta}\right)\left(\Delta p^{\prime}=0\right)$, and they should be determined experimentally, according to the concept proposed by Sawicki (2008), see also Sawicki and Świdziński (2010).

The generalised coefficient of compressibility of the skeleton corresponding to isotropic compression was determined for the same tailings that were used to study the effect of partial saturation on the soil response to triaxial compression under 


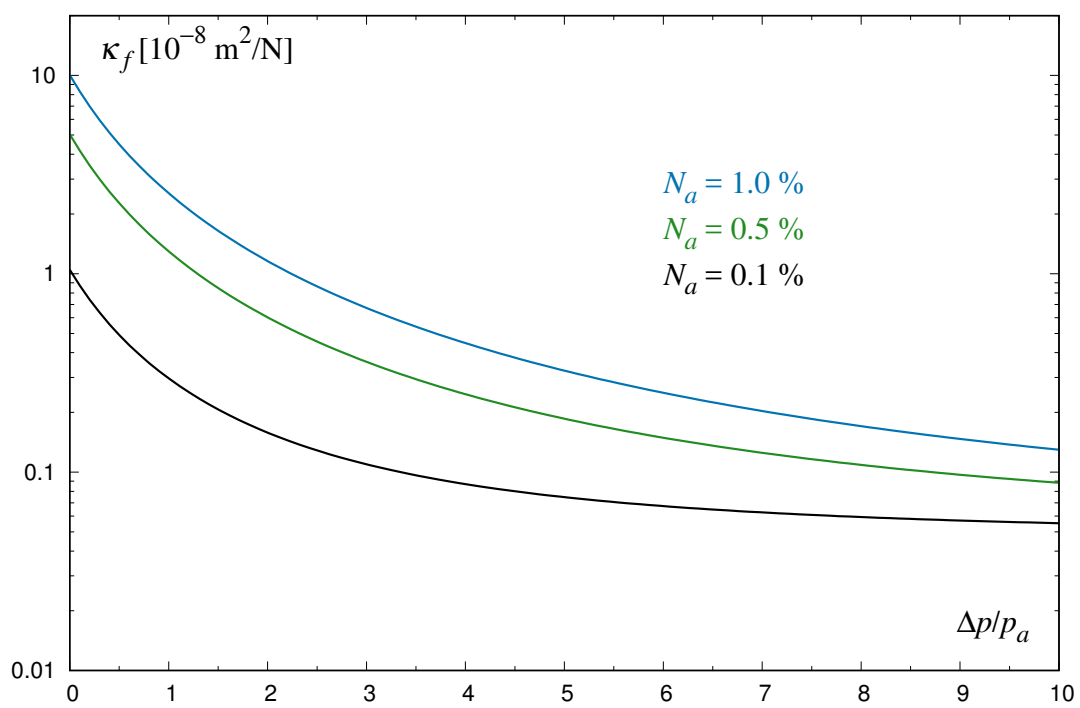

Fig. 6. Water-gas mixture compressibility as a function of pressure for different air contents

Table 1. Index properties of tailings taken from the TSF Żelazny Most at a distance of $50 \mathrm{~m}$ from the dam's crest (Os50)

\begin{tabular}{|c|c|c|c|c|c|c|c|c|}
\hline $\begin{array}{c}w_{n} \\
{[\%]}\end{array}$ & $\begin{array}{c}\rho_{s} \\
{\left[\mathrm{~g} / \mathrm{cm}^{3}\right]}\end{array}$ & $\begin{array}{c}\rho_{\max } \\
{\left[\mathrm{g} / \mathrm{cm}^{3}\right]}\end{array}$ & $\begin{array}{c}\rho_{\min } \\
{\left[\mathrm{g} / \mathrm{cm}^{3}\right]}\end{array}$ & $\begin{array}{c}e_{\max } \\
{[-]}\end{array}$ & $\begin{array}{c}e_{\min } \\
{[-]}\end{array}$ & $\begin{array}{c}d_{50} \\
{[\mathrm{~mm}]}\end{array}$ & $\begin{array}{c}D<0.075 \\
{[\%]}\end{array}$ & $\begin{array}{c}\text { SFR } \\
{[-]}\end{array}$ \\
\hline 5.83 & 2.675 & 1.63 & 1.32 & 1.026 & 0.643 & 0.157 & 5.8 & 15.67 \\
\hline
\end{tabular}

undrained conditions, Świdziński et al (2017). The values of the basic index properties of that soil are summarised in Table 1.

The coefficient of soil skeleton compressibility corresponding to compression $\kappa_{s}{ }^{\prime}$ was determined from anisotropic consolidation studies ( $\eta=$ const) by measuring volume changes in dry soil. Investigations were carried out under anisotropic consolidation for $\eta=0.7$ (Fig. 7). For practical reasons, a preliminary vacuum of $20 \mathrm{kPa}$ was applied to the samples of sandy sediments, which were reconstituted in the laboratory. This made it possible to maintain a fixed soil density throughout the entire sample preparation phase. Thus, anisotropic consolidation began from this pressure, not from zero.

Figure 7 shows two consolidation curves obtained for samples of Os50 tailings. These curves were approximated by the logarithmic function

$$
\varepsilon_{v}=A_{p} \ln \left[1+B_{p}\left(\frac{p^{\prime}}{p_{0}}-0.2\right)\right]
$$

where $A_{p}$ and $B_{p}$ are coefficients, the value of 0.2 corresponds to an initial effective stress of $20 \mathrm{kPa}$. The values of the coefficients $A_{p}$ and $B_{p}$ were determined by the least squares method and are equal to $20.68 \times 10^{-3}$ and 2.86 , respectively. 


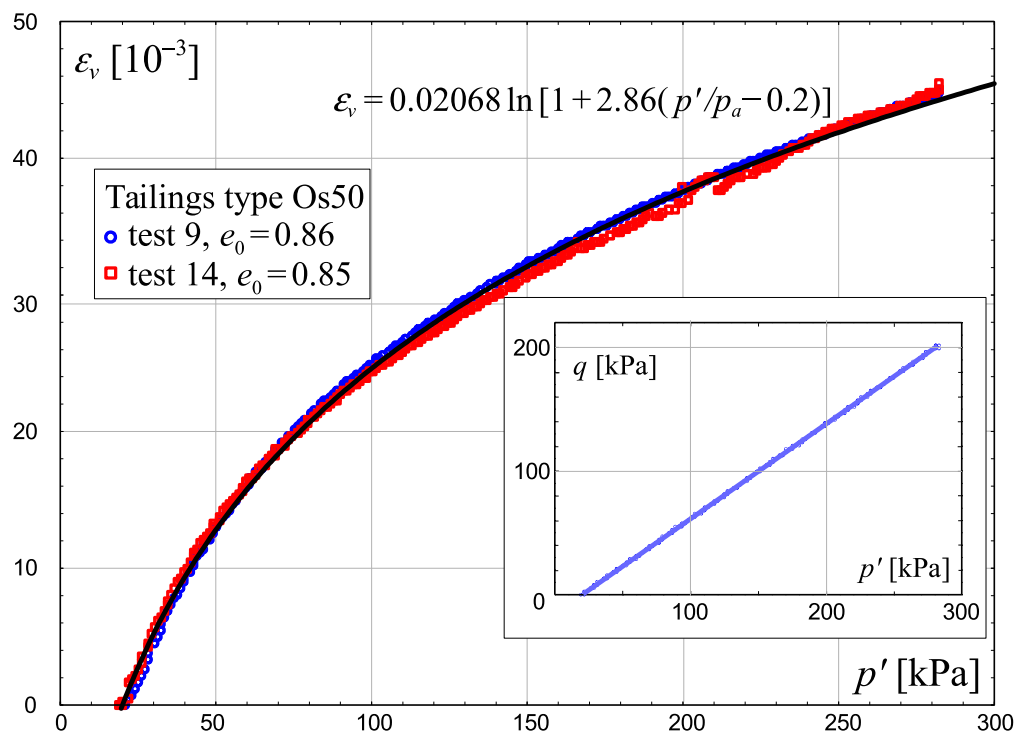

Fig. 7. Sediment volume change caused by anisotropic consolidation $(\eta=$ const $=0.7)$

According to Eq. (27), the soil skeleton compressibility corresponding to isotropic compression $\kappa_{s}{ }^{p^{\prime}}$ for the tailings tested will be as follows:

$$
\kappa_{s}^{p^{\prime}}=\frac{d \varepsilon_{v}}{d p^{\prime}}=\frac{1}{p_{a}} \frac{A_{p} B_{p}}{1+B_{p}\left(\frac{p^{\prime}}{p_{0}}-0.2\right)} .
$$

In the same way, the second of the generalised coefficients of soil skeleton compressibility is determined by the pure shearing test $\left(p^{\prime}=\right.$ const) at different values of $p^{\prime}$. In this case, the approximation of experimental results can be described as follows:

$$
\varepsilon_{v}=A_{\eta} \exp \left[B_{\eta}\left(\eta_{C M}-\eta\right)\right]
$$

where $\eta_{C M}$ corresponds to the Coulomb-Mohr yield surface for the non-cohesive soils tested. On the basis of the available results of experiments conducted on different soil specimens, the following coefficients were used: $A_{\eta}=30.0 \times 10^{-3}$ and $B_{\eta}=2.8$.

As before, based on Eq. (28), the generalised coefficient of compressibility of the soil skeleton under pure shearing $\left(p^{\prime}=\right.$ const) for different values of $p^{\prime}$ will take the form

$$
\kappa_{s}^{\eta}=\frac{d \varepsilon_{v}}{d \eta}=A_{\eta} B_{\eta} \exp \left[B_{\eta}\left(\eta-\eta_{C M}\right)\right]
$$




\section{Theoretical Prediction of Experimental Data}

The results of numerical integration of Eq. (32), along with Eq. (33) and functions (35) and (37), were compared with the results of experiments conducted on partially saturated samples of tailings subjected to undrained triaxial compression described in detail by Świdziński et al (2017).

The research was carried out on specimens reconstituted by the moist tamping method, (see Świdziński and Mierczyński 2003, 2005), which ensured full control of the initial density of each sample. Having been formed to a specified density, the samples were saturated with water to various saturation degrees, controlled by the value of Skempton's coefficient $B$. Higher saturation values were achieved by the standard technique, which consists in removing the air from a dry sample by replacing it with carbon dioxide and slow flushing with water. Lower saturation, on the other hand, was achieved either by omitting carbon dioxide flushing or by reducing back pressure, and sometimes by using non-deaired water in the pressure controller used in the saturation process. As a result of different techniques, the saturation of soil pores with water expressed by Skempton's coefficient was different, ranging from $B=0.29$ to $B=0.93$.

The values of the initial void ratios and Skempton's coefficient for soil samples subjected to monotonic loading, as well as the values of back pressure applied, are summarised in Table 2.

Table 2. Initial values of void ratios and Skempton's coefficients for samples subjected to monotonic triaxial compression (Świdziński et al 2017)

\begin{tabular}{|c|c|c|c|c|c|c|}
\hline No. & $\begin{array}{c}e_{0} \\
{[-]}\end{array}$ & $\begin{array}{c}n \\
{[-]}\end{array}$ & $\begin{array}{c}D_{R} \\
{[\%]}\end{array}$ & $\begin{array}{c}B \\
{[-]}\end{array}$ & $\begin{array}{c}u_{0} \\
{[\mathrm{kPa}]}\end{array}$ & $\begin{array}{c}q_{\max } \\
{[\mathrm{kPa}]}\end{array}$ \\
\hline $\mathrm{m} 1$ & 0.89 & 0.470 & 24 & 0.93 & 300 & 154.4 \\
\hline $\mathrm{m} 2$ & 0.87 & 0.465 & 41 & 0.92 & 200 & 172.0 \\
\hline $\mathrm{m} 3$ & 0.86 & 0.462 & 43 & 0.84 & 100 & 223.4 \\
\hline $\mathrm{m} 4$ & 0.84 & 0.465 & 49 & 0.55 & 100 & 389.7 \\
\hline $\mathrm{m} 5$ & 0.84 & 0.465 & 49 & 0.74 & 150 & 305.0 \\
\hline $\mathrm{m} 7$ & 0.85 & 0.459 & 46 & 0.39 & 50 & 648.9 \\
\hline $\mathrm{m} 8$ & 0.89 & 0.470 & 36 & 0.29 & 10 & 571.5 \\
\hline
\end{tabular}

In order to isolate the effect of different saturation levels on the response of the soil under investigation, all samples were isotropically consolidated to the same effective consolidation pressure $p^{\prime}=400 \mathrm{kPa}$ and subsequently subjected to triaxial compression at a constant cell pressure and at a controlled strain rate of $10 \% / \mathrm{h}$. The tests were conducted to a vertical strain of more than $25 \%$ until a steady state was reached.

As shown in Table 2, thanks to the careful control of the initial density, very high repeatability was obtained for each of the specimens tested. The average initial void ratio of all samples was 0.865 , which corresponds to the medium dense soil $\left(D_{R}=\right.$ 
0.42 ), with a slight standard deviation of 0.02 . For porosity, it was 0.465 with the same standard deviation. All samples were characterised by an initial contractive state.

Figure 8 shows the results of test $\mathrm{m} 3$ in the space of the stress deviator-mean effective stress $\left(q, p^{\prime}\right)$, in which the level of saturation expressed by Skempton's coefficient was $B=0.84$.

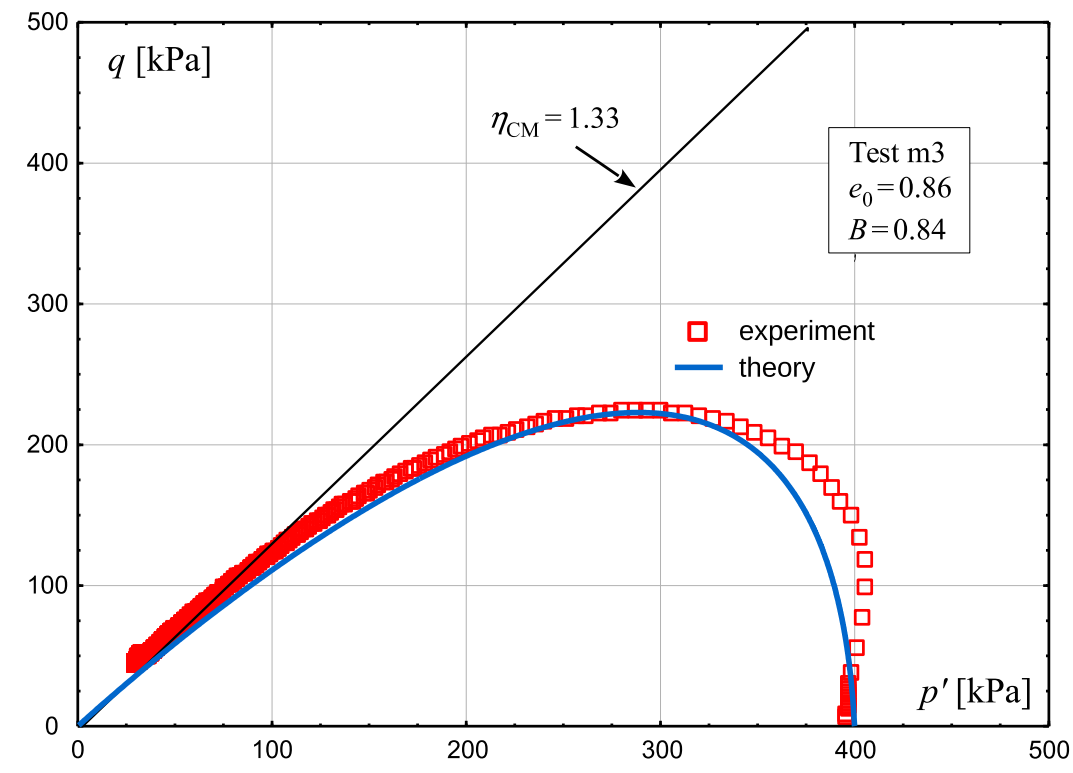

Fig. 8. Theoretical prediction of results of test $m 3$

As can be seen in Fig. 8, the theoretical prediction of the model described in Section 3 agrees with the test results very well, both qualitatively and quantitatively. The only slight differences exist in the initial and final phases of the stress path. In the first case, it is the question of the appropriate selection of functions describing the experiments carried out to determine the generalised coefficients of soil compressibility $\kappa_{s}{ }^{\prime}$ and $\kappa_{s}{ }^{\eta}$, see Section 3.3. In the second case, the model does not incorporate a procedure for limiting residual shear strength under undrained conditions, which would require the construction of an additional model describing the behaviour of soil that has reached the steady state (see Świdziński and Mierczyński 2005). However, despite these slight differences, in the case of test $\mathrm{m} 3$, the theoretical prediction closely matches the results of the experiment.

Figure 9 shows stress paths for all monotonically loaded samples. Moreover, in the same figure, a stress path corresponding to the response of dry or fully drained soil is presented (green solid line).

The results presented in Fig. 9 indicate a regular response of the samples, except in test $\mathrm{m} 7$, in which an unexpected drop in the deviator occurred (black stress path). Also regular is the relationship between the soil response and the sample saturation 


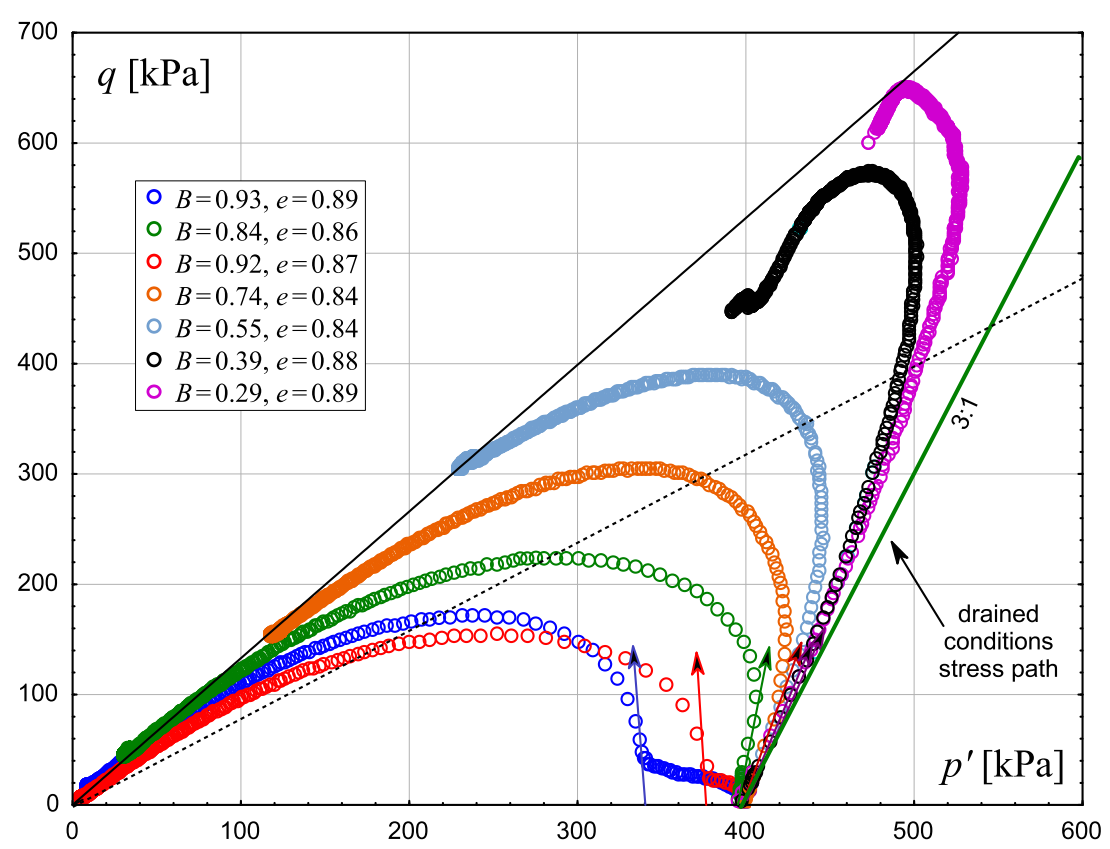

Fig. 9. Response of tailings samples for different levels of partial saturation under undrained conditions

level expressed by Skempton's coefficient $B$ : as $B$ decreases, the shear strength of the sample increases (higher maximum value of the stress deviator, smaller its post-peak decrease, lower excess pore pressure generated).

It is also important that the slope of the tangent to the stress path (just after the deviator rises above zero) changes depending on the level of saturation. For lower saturation levels, the initial part of the stress path is closer to that under fully drained conditions.

Figure 10 shows theoretical predictions of stress paths for different values of the coefficient $B$ corresponding to those applied in the triaxial tests, see Table 2 .

By comparing the experimental and theoretical stress paths for different values of the coefficient $B$ (Figs. 9 and 10 respectively), we can see very good qualitative agreement between paths corresponding to the same values of $B$. The shapes of the experimental and theoretical paths are very similar, reflecting the decrease in the mean effective stress as the load increases. In addition, the shear strength expressed by the maximum value of the stress deviator increases with decreasing $B$, and the tangent to the stress path deflects towards the path corresponding to fully drained conditions $(B=0)$.

Much worse is the quantitative agreement of the corresponding paths. It is very good only in the case of test $\mathrm{m} 3(B=0.84)$ (Figure 8$)$. In the other cases, the theoretical prediction slightly overstates stress paths for higher values of $B$ and strongly underestimates them for lower saturation levels $(B<0.84)$. 


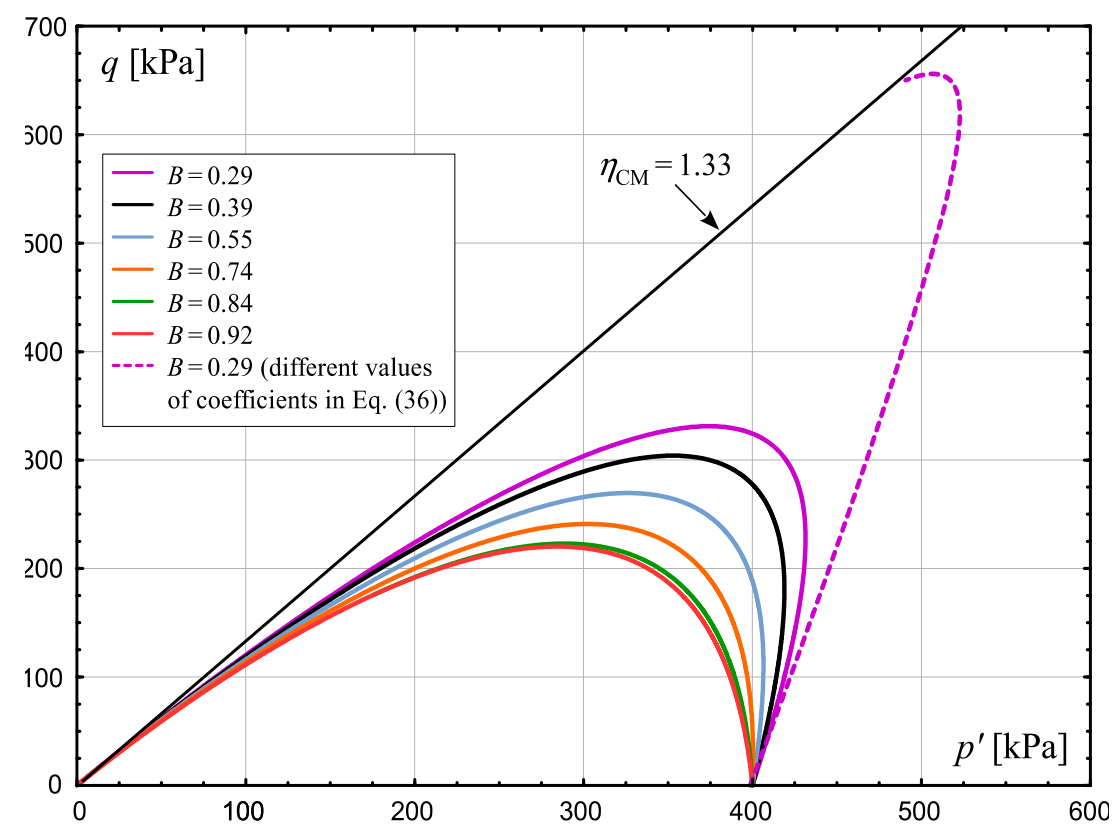

Fig. 10. Theoretical prediction of test results presented in Fig. 9

Parametric tests for the case of the lowest saturation $(B=0.29)$ allowed us to find values of the parameters $A_{\eta}$ and $B_{\eta}$ describing the generalised compressibility coefficient of the soil skeleton $\left(p^{\prime}=\right.$ const, Eq. (37)) that give a better match with experimental data. Such an agreement was obtained for $A_{\eta}=3.0$ and $B_{\eta}=5.8$ (see Figs. 9 and 10 - highest stress paths). This means that the proposed theoretical model provides good predictions of experimental results in terms of quantity. However, it requires a better determination of the soil compressibility coefficient during pure shearing $\left(p^{\prime}=\right.$ const $)$.

\section{Summary}

The original theoretical model describing the response of partially saturated non-cohesive soil subjected to undrained triaxial compression was presented. The proposed model is given by a differential equation based on the concept originally proposed by Skempton (1954) and later developed by Sawicki (2008). The integration of this equation makes it possible to reconstruct the stress path in the $\left(p^{\prime}, q\right)$ space for any value of Skempton's coefficient $B$. Important elements of the proposed model are the coefficient of compressibility of pore fluid $\kappa_{f}$ (which is a mixture of water and gas) and generalised compressibility coefficients of the soil skeleton under isotropic compression $\kappa_{s}{ }^{\prime} \quad\left(\eta=\right.$ const) and pure shearing $\kappa_{s}^{\eta}\left(p^{\prime}=\right.$ const). In general, these coefficients are functions of the soil state (void ratio) and the stress state expressed by the mean effective stress and the deviator stress. These functions should be determined 
experimentally for a particular type of soil in triaxial compression tests for different stress conditions.

The proposed theoretical model was confronted with experimental data. Very good qualitative consistency of the corresponding stress paths was obtained for the same $B$ values. Quantitative consistency was not satisfactory, because the model slightly underestimated the results of experiments for low values of Skempton's coefficient $B$, and overestimated them for high $B$ values. This may be due to the lack of suitable experimental data on the tested material as well as to the imperfect selection of the function describing the general coefficient of compressibility of the soil skeleton under pure shearing. The research will be continued.

The proposed model can also have a great practical significance, because studies by other authors indicate that artificial airing of saturated soil can significantly reduce the level of pore water saturation, and this condition can persist for decades, e.g. Okamura et al (2006). Therefore, this could be an effective way to reduce the liquefaction hazard under natural conditions. It would also require to theoretically describe pore pressure generation and the liquefaction susceptibility of partially saturated soils, and such is the purpose of the proposed theoretical model.

\section{References}

Bian H., Shahrour I. (2009) A numerical model for unsaturated soils under seismic loading - application to liquefaction, Journal Soil Dynamics and Earthquake Engineering, 29(2), 237-244.

Fredlund, D. G. (1976): Density and compressibility characteristics of air-water mixtures, Canadian Geotechnical Journal, 13(4), 386-396.

Fredlund D. G., Rahardjo H. (1993) Soil mechanics for unsaturated soils, Wiley, New York.

Geoteko (2012) The report on laboratory tests of undisturbed tailings samples taken from TSF Żelazny Most, commissioned by O/ZH KGHM POLSKA MIEDŹ S.A. (in Polish).

Ishihara K., Tsukamoto Y., Kamada K. (2004) Undrained behaviour of near-saturated sand in cyclic and monotonic loading, In: Triantafyllidis Th. (ed.), Cyclic Behaviour of Soils and Liquefaction Phenomena, Taylor \& Francis Group, London, 27-39.

Jamiolkowski M. (2014) Soil mechanics and the observational method: challenges at the Zelazny Most copper tailings disposal facility, Géotechnique, 64(8), 590-618, doi: 10.1680/geot.14.RL.002.

Kamata T., Tsukamato Y., Ishihara K. (2009) Undrained shear strength of partially saturated sand in triaxial tests, Bulletin of the New Zealand Society for Earthquake Engineering, 42(1), 57-62.

Mierczyński J. (2001) Mechanics of the process of extrication of object from the water saturated subsoil, $\mathrm{PhD}$ thesis, Institute of Hydro-Engineering, IBW-PAN (in Polish).

Nakazawa H., Ishihara K., Tsukamoto Y., Kamata T. (2004) Case studies on evaluation of liquefaction resistance of imperfectly saturated soil deposits, In: Triantafyllidis Th. (ed.), Cyclic Behaviour of Soils and Liquefaction Phenomena, Taylor \& Francis Group, London, 295-304.

Okumura M., Ishihara M., Tamura K. (2006) Degree of saturation and liquefaction resistance of sand improved with sand compaction piles, Journal Geotech., Geoenviron., Engrg., ASCE, 132(2), 258-264.

Sawicki A. (2008) 3D and 2D formulation of incremental stress-strain relations for granular soils, Arch. of Hydro-Engineering and Environ. Mech., 55(1-2), 45-53.

Sawicki A., Świdziński W. (2007) Drained against undrained behaviour of granular soils, Arch. of Hydro-Engineering and Environ. Mech., 54(3), 207-222. 
Sawicki A., Świdziński W. (2010) Stress-strain relations for dry and saturated sands, Part I: Incremental model, Jnl Theoretical and Applied Mechanics, 48(2), 309-328.

Skempton A. W. (1954) The pore pressure coefficients A and B, Géotechnique, 4, 143-147.

Świdziński W., Mierczyński J. (2003) Determination of steady state line for sands, Inżynieria Morska i Geotechnika, 24(3/4), 194-199 (in Polish).

Świdziński W., Mierczyński J. (2005) Instability line as a basic characteristic of non-cohesive soils, Arch. of Hydro-Engineering and Environ. Mech., 52(1), 59-85.

Świdziński W., Mierczyński J. and Mikos A. (2017) Response of partially saturated noncohesive soils, Arch. of Hydro-Engineering and Environ. Mech., 64(3-4), 187-207, doi: 10.1515/heem-2017-0012.

Verruijt A. (1969) Elastic storage of aquifers, In: De Wiest R. J. M. (ed.), Flow Through Porous Media, Academic Press, New York, 331-376.

Yang J. (2002) Liquefaction resistance of sand in relation to P-wave velocity, Géotechnique, 52(4), 295-298.

Yang J., Savidis S., Roemer M. (2004) Evaluating liquefaction strength of partially saturated sand, Jnl of Geotechnical and Geoenvironmental Eng. ASCE, 130(9), 975-979, doi: 10.1061/(ASCE)1090-241. 